\title{
ASSOCIATION OF DIESEL EXHAUST PARTICLE EXPOSURE WITH ERYTHROCYTES DEFORMATION OF MALE MICE
}

\author{
WARDOYO, A. Y.P.* - JUSWONO, U. P. - NOOR, J. A. E. \\ Laboratory of Air Quality and Astro Imaging, Department of Physics, Brawijaya University \\ Jl. Veteran 65145, Malang, East Java, Indonesia \\ (phone: +62-341-575-833; fax: +62-341-585-834) \\ *Corresponding author \\ e-mail:a.wardoyo@ub.ac.id \\ (Received 26 $6^{\text {th }}$ Jun 2018; accepted $14^{\text {th }}$ Aug 2018)
}

\begin{abstract}
Many epidemiological studies, whether in vivo or in vitro in human or mammals indicate that particulate matters emitted by diesel vehicles have impacts on health. While the effects of daily particulate matter exposure have been well reviewed, the physiological evidence of mice blood alteration associated with the exposure to the diesel exhaust particles has not been investigated well. In this study, we examined the association between the exposure to ultrafine particles contained in the diesel exhaust emission and mice erythrocyte deformation. Ultrafine particles (diameter: $0.02 \mu \mathrm{m}$ to $0.10 \mu \mathrm{m}$ ) were filtered from three different diesel engine cars. There were 50 male mice used as the experimental animals. The mice were exposed to the ultrafine particles in the different concentration for eight consecutive days. The total concentration of ultrafine particles was measured using a P-Trak Ultrafine Particle Counter (TSI, Model 8525). The mice were sacrificed after the eight-day exposures. The blood samples were observed using a Binocular BX-51 Computer Microscope to examine the level of erythrocyte deformation. The results showed that the increasing amount of the ultrafine particle concentrations caused the increasing extent of the erythrocytes deformation level significantly.

Keywords: particulate matter, ultrafine particle, diesel vehicle, mice erythrocyte, deformation level
\end{abstract}

\section{Introduction}

Diesel engines are widely used as a rapid mass transportation mode. The increasing amount of diesel engines is correlated with the exhaust emission. One of the problems with the diesel engine use is the exhaust particles. Diesel exhaust particles are the particles that generated from a diesel engine and become the major constituents of the ambient air pollutant. They consist of ultrafine particles or $\mathrm{PM}_{0.1}$ (particulate matter with an aerodynamic diameter $\leq 0.1 \mu \mathrm{m}$ ) (Waly et al., 2013), $\mathrm{PM}_{1}$ (particulate matter with an aerodynamic diameter $\leq 1 \mu \mathrm{m}$ ) (Xu et al., 2013, Wierzbicka et al., 2014), and $\mathrm{PM}_{2.5}$ (particulate matter with an aerodynamic diameter $<2.5 \mu \mathrm{m}$ ) (Hemmingsen et al., 2009). Considering toxicity level, ultrafine particles, as the smallest particulate matter has become a prevalent problem in the whole world regarding both quality and quantity.

There is a well-established correlation between exposure to ultrafine particles emission and health and environment. Inhalation of ultrafine particles increases the risk of adverse health effects associated with the endothelial progenitor cells (Jantzen et al., 2016), abnormal sedimentation, hemagglutination, dose-dependent hemolysis in erythrocytes (Li et al., 2008), increasing of oxidative stress in human embryonic kidney cells (Wang et al., 2009), and a potential risk for atherosclerotic vascular disease (Stewart et al., 2010). Especially the impacts of ultrafine particles in the blood, the erythrocyte deformation or the morphological changes may relate to the abnormal function of blood. Any alteration due to erythrocytes deformation become a marker of iron deficiency anemia and thalassemia (Zhang et al., 2012). Similarly, a previous study 
showed that the erythrocyte deformation was related to the sickle cell disease (Charrin et al., 2016). Our previous studies confirmed the correlation between the exposure to particulate matters from motorcycle exhaust emission and the cell deformations in mice model, in red blood cells (Wardoyo et al., 2017) and kidney cells (Wardoyo et al., 2018). However, there are no published novel data reporting the trends of ultrafine particles concentration from diesel exhaust emission and erythrocyte cell alteration, which are determined useful for investigating a deeper impact of particulate matters emission in the road traffic. Furthermore, the degree to which ultrafine particles from heavy vehicles mean a risk in the organ is a scientific scope that has not previously been tested by direct exposure in human and experimental animals. Although there have been numerous researchers that investigated this case, the sharp mechanisms and effects of the ultrafine particles in the erythrocytes are poorly understood. In this study, exposure to the ultrafine particles focused on the diesel exhaust emission (as a heavy-duty motor vehicle) was chosen due to the negative impact possibilities in health, i.e., in mice erythrocytes. This study is also needed to develop a biomarker for assessing a better understanding of the effect of the ultrafine particles for an acute exposure in the blood.

\section{Materials and Methods}

\section{Ultrafine Particles}

Three diesel engine cars (D1, D2, and D3) were preferred as the motor samples chosen based on the availability around the University of Brawijaya Malang, Indonesia. The diesel exhaust emission was filtered using a particulate filtering system that consists of an N95 particulate respirator (3M, Model 8210) and a sucking pump (constant debit: $33.05 \mathrm{~cm}^{3} / \mathrm{s}$; flow rate: $2.03 \mathrm{~m} / \mathrm{s}$ ) as described in our previous study (Wardoyo et al., 2018). The filtered ultrafine particles (diameter: $0.02 \mu \mathrm{m}$ to $0.10 \mu \mathrm{m}$ ) were injected into the exposure chambers in three different injection times $(20-60$ seconds) in order to generate the varied ultrafine particle concentrations of $\mathrm{C} 1$ (20 seconds), C2 (40 seconds), and C3 (60 seconds). The concentrations of the ultrafine particles were measured using a P-Trak Ultrafine Particle Counter (TSI, model 8525) (Fig. 1) (Wardoyo et al., 2007). The different injection times were used to generate different concentrations of ultrafine particles.

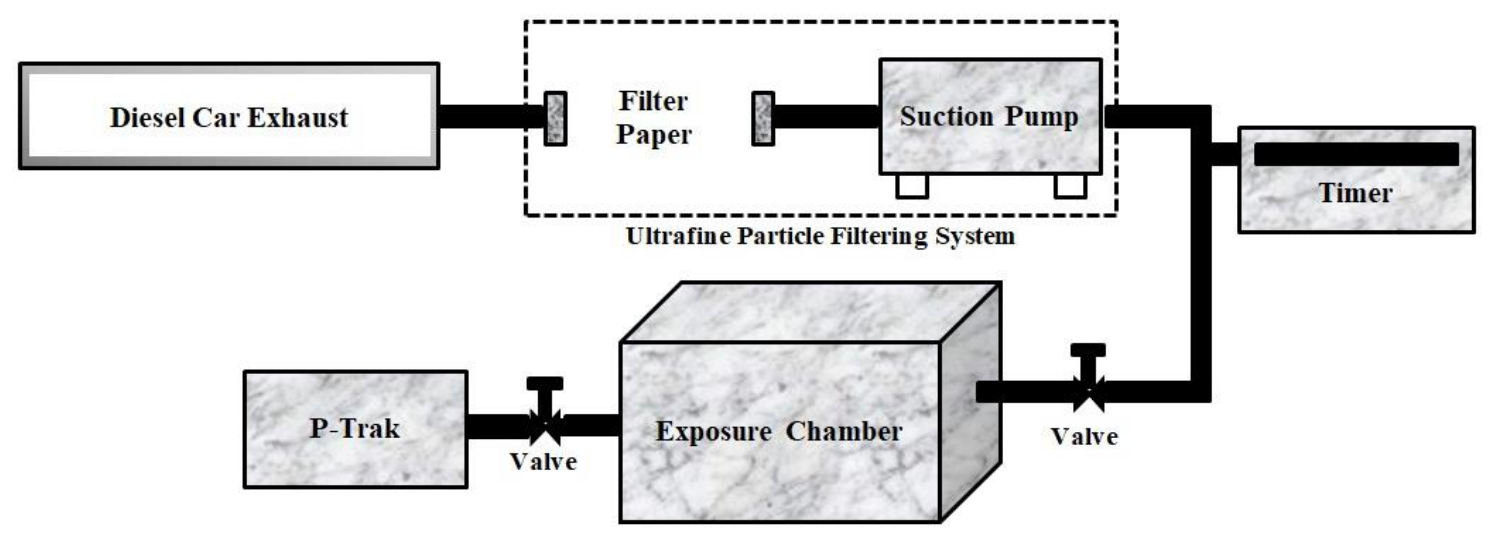

Figure 1. The schematic of the ultrafine particle concentration measurements 


\section{Experimental Animals and Treatments}

The study included 50 male Wistar mice (12 weeks old, body weight: 21 - $23 \mathrm{~g}$ ). All mice were treated humanely, provided with water and foods ad libitum, and kept under controlled light (12:12 dark-light cycle) and room temperature $\left(27.4-28.1^{\circ} \mathrm{C}\right)$. An acclimatization period of three days was allowed for the mice before any exposure treatment. All animal treatment procedures were approved by the Animal Care and Use Committee of Brawijaya University Malang, Indonesia (Ethical Clearance number: 541KEP-UB).

After the acclimation, the mice were randomly divided into a control group $(\mathrm{C} 0)$ - the group of unexposed mice $(\mathrm{n}=5)$ - and the exposure groups $(\mathrm{C} 1, \mathrm{C} 2$, and $\mathrm{C} 3, \mathrm{n}=5$ per car sample per group). The mice from $\mathrm{C} 1$ groups were exposed to the ultrafine particles with the car sample D1, D2, and D3 with the injection time of 20 seconds. The mice from C2 and C3 groups were exposed to the ultrafine particles with the car sample D1, D2, and D3 with the injection times of 40 and 60 seconds, respectively. The exposures were conducted for 100 seconds on eight consecutive days (100 seconds per day). Our previous research gave us information that the mice collapsed more than eight days after the exposure. After the last day of the exposure, all mice were sacrificed using a cervical vertebra dislocation method in order to take the blood drop samples. The blood was collected in tubes, and the smears were made on object glasses and fixed with methanol solutions $(70 \%)$. When they came dried ( \pm 5 minutes), they were colored using Giemsa-buffer pro-Giemsa solution (1:3) as long as 15 minutes. The samples were washed in running tap water. Any section showing abnormal morphology caused by the drying procedure was discarded.

\section{Deformation Calculation}

Digital images of the blood samples were taken with a 400x magnification of areas can reliably be judged from an overall evaluation of the slide. Five different investigators scored random fields of view using a Binocular BX-51 Computer Microscope (Wang et al., 2017, Cannizzaro et al., 2009). The deformation level (DL) of the mice erythrocytes was calculated using equation (1) (Wardoyo et al., 2017). The total of deformed and normal erythrocytes were averaged from those ten fields of view for each animal and then averaged from 5 animals.

$$
D L=\frac{\sum \text { deformed erythrocytes }}{\sum \text { erythrocytes }} \times 100 \%
$$

\section{Statistical Analysis}

Values are expressed as the means $\pm \mathrm{SD}$ (standard deviation). The differences between two groups ( $\mathrm{C} 0$ and an exposure group) were evaluated using a Student's $t$-test. We compared the results obtained in the control group and the D1 group, the control group and the D2 group, and the control group and the D3 group. The association between the exposure to the ultrafine particles and the erythrocyte deformation level was interpreted by a linear regression analysis using Microsoft Excel 2016. $R^{2}>0.85$ was considered as significantly correlated, and $p<0.05$ was considered to show statistical significance (Eeftens et al., 2015). 


\section{Results}

\section{Ultrafine Particles Concentration}

The concentrations of ultrafine particles mice were exposed to for eight consecutive days are presented in Table 1. Based on the measurement results, a longer time needed to inject the exhaust emission to the exposure chamber generates a higher ultrafine particle concentration. Compared to $\mathrm{C} 1$, the concentrations of $\mathrm{C} 2$ and $\mathrm{C} 3$ are higher, in which the highest concentration is found in $\mathrm{C} 3$. On the other hand, the lowest ultrafine particle concentration is found in $\mathrm{C} 1$.

Table 1. Ultrafine particles concentration mice were exposed to(mean $\pm S D)$

\begin{tabular}{cccc}
\hline \multirow{2}{*}{ Ultrafine Particle Concentrations } & \multicolumn{3}{c}{ Ultrafine Particles } \\
\cline { 2 - 4 } & D1 & D2 & D3 \\
\hline C1 & $3.65 \pm 0.04$ & $2.26 \pm 0.02$ & $1.03 \pm 0.10$ \\
C2 & $4.87 \pm 0.26$ & $2.87 \pm 0.16$ & $1.10 \pm 0.07$ \\
C3 & $5.46 \pm 0.35$ & $3.28 \pm 0.08$ & $1.22 \pm 0.01$ \\
\hline
\end{tabular}

\section{Deformation Level}

The digital images used to observe histological changes (deformation) in the mice erythrocytes are shown in Fig. 2. The erythrocytes in those examples are obtained from the control and the exposure groups. The control group is used to observe the native deformation of the healthy mice (normal mice, without exposure). According to Fig. 2, there are significant differences in the deformation level between the control mice and the exposed mice. The normal erythrocytes are interpreted as the red circles, and the abnormal ones are shown by the black circles. A normal erythrocyte has a biconcave shape. The abnormal erythrocytes are obtained as (1) teardrop-shaped, (2) helmetshaped cells, (3) sickle-shaped cells, (4) ovalocytes, (5) saddle-shaped, and (6) stomatocytes (Zhang et al., 2009). Table 2 below interprets the calculated deformation levels of the mice erythrocytes.

Table 2. Deformation levels from the control and exposure groups $(p<0.05$ between two groups: the control group and an exposure group)

\begin{tabular}{cccc}
\hline \multirow{2}{*}{ Ultrafine Particle Concentration } & \multicolumn{3}{c}{ Deformation Levels (\%) } \\
\cline { 2 - 4 } & D1 & D2 & D3 \\
\hline Control & $12 \pm 1$ & $12 \pm 1$ & $12 \pm 1$ \\
C1 & $32 \pm 1$ & $31 \pm 1$ & $25 \pm 2$ \\
C2 & $33 \pm 3$ & $32 \pm 1$ & $26 \pm 1$ \\
C3 & $35 \pm 2$ & $33 \pm 3$ & $29 \pm 1$ \\
\hline
\end{tabular}

Figure 2 shows that the exposure of ultrafine particles with the concentration of $\mathrm{C} 1$ induces a significant increase in the deformed erythrocytes compared to the control group. It has been observed that the exposure to ultrafine particles with the 
concentration of $\mathrm{C} 1$ induced $110 \pm 5,119 \pm 3$, and $93 \pm 9$ deformed erythrocytes in D1, D2, and D3 car samples, respectively. In the group of C2, the exposed ultrafine particles significantly decrease the number of normal erythrocytes compared to the control group ( $245 \pm 7$ cells). The deformed erythrocytes in the group of C2 for the car sample D1, D2, and D3 are $103 \pm 11$ cells, $111 \pm 6$ cells, and $99 \pm 5$ cells, respectively. Similarly, a significant difference is also found in the other exposure group among the $\mathrm{C} 3$ and the control groups. The erythrocyte deformation in the group of $\mathrm{C} 3$ for the car sample D1, D2, and D3 involved $107 \pm 5$ cells, $135 \pm 16$ cells, and $81 \pm 5$ cells, respectively.

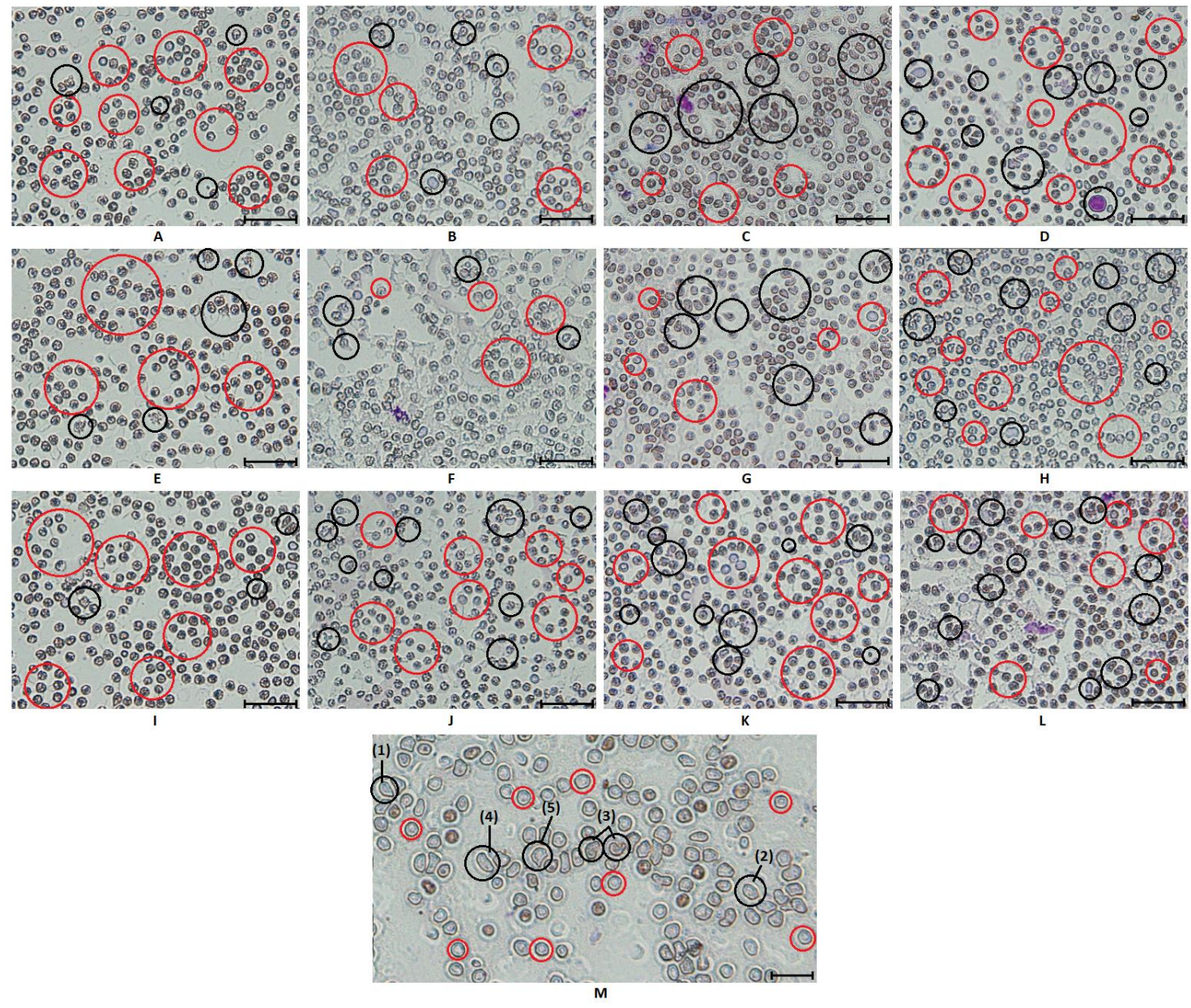

Figure 2. Digital images from the control group (A; E; and I) and the treatment groups, with 400x of magnification (scale bar: $30 \mu \mathrm{m}$ ): $B-D=C 1$ groups; $F-H=C 2$ groups; and $J-L=C 3$ groups. The normal and deformed erythrocytes $(M)$, scale bar: $20 \mu \mathrm{m}$

\section{Ultrafine Particle Concentration vs Deformation Level}

For a better understanding, Fig. 3 depicts the correlation between the exposure to the ultrafine particles and the deformation levels of the mice erythrocytes (D1-D3). In order to investigate the influence of the exposure to ultrafine particles, the deformation levels of the mice erythrocytes were alleviated by the deformation level obtained in the control group. The correlation between the ultrafine particle concentration and the erythrocyte deformation was interpreted in a linear regression. In the car sample of D1, the 
increasing amount of the ultrafine particle concentrations increase the level of erythrocytes deformation $\left(R^{2}=0.86\right)$. Interestingly, the similar trend is found in the different car samples D2 $\left(R^{2}=0.99\right)$ and D3 $\left(R^{2}=0.98\right)$. The increased concentrations of ultrafine particles in the diesel exhaust emission cause more deformation on the erythrocytes. Based on Fig. 3, it is confirmed that a higher dose of ultrafine particles enhanced the deformation levels compared to the control group (see Table 2). The figure above shows that the concentration of the ultrafine particles contained in the car exhaust emission had direct influences on the mice erythrocytes deformability $\left(R^{2}>\right.$ $0.85)$. All graphs indicate a high correlation, since the values of each $R^{2}$ approach 1 .

(A)

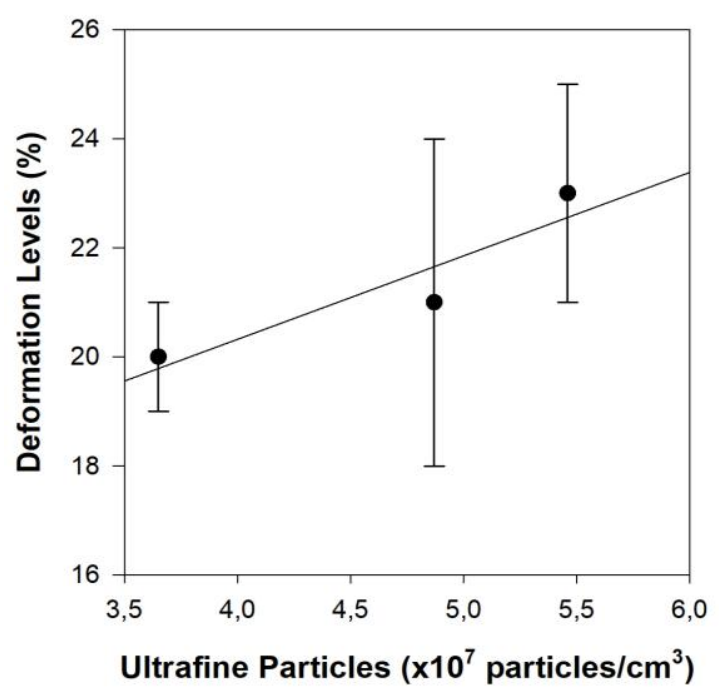

(B)

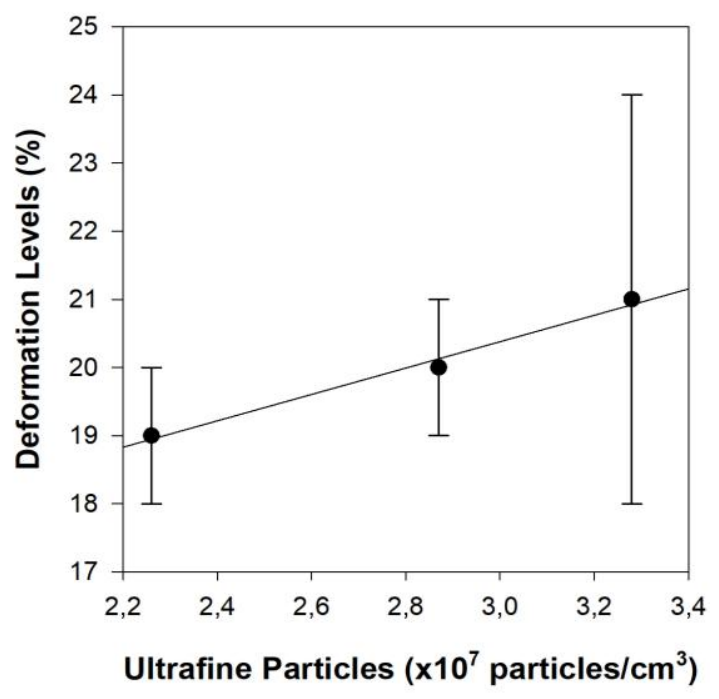

(C)

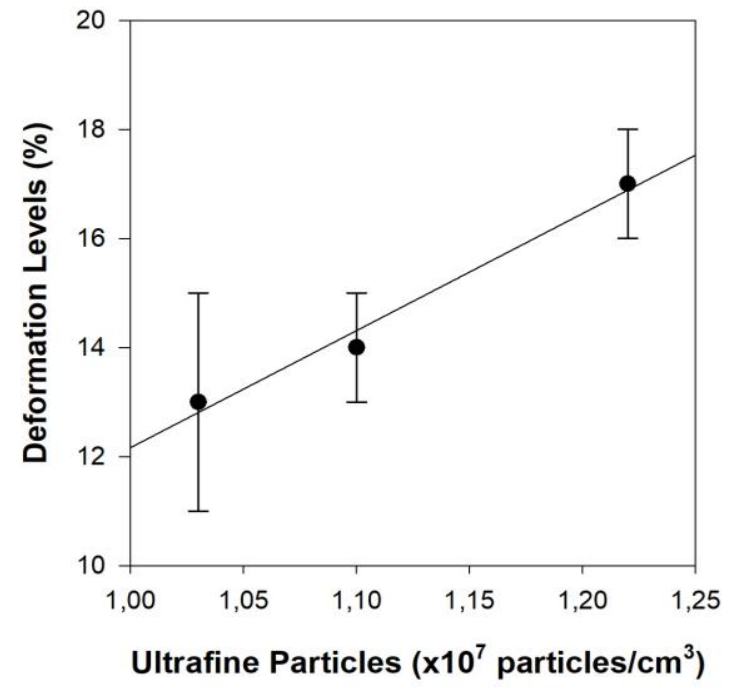

Figure 3. The correlations between the concentration of ultrafine particles in the car exhaust smoke and the mice erythrocytes deformation: A). D1; B). D2; and C). D3 


\section{Discussion}

The present study of the erythrocyte deformability is of great importance in hemorheology. This study reveals a novel association between exposure to ultrafine particles contained in the exhaust emission emitted by diesel engine cars and mice erythrocytes deformation. The deformation was indicated by the alteration in the erythrocyte shape that might be related to the erythrocyte function in the body system. As we know, a normal erythrocyte needs flexibility in transporting gases in the body. A biconcave shape of a normal erythrocyte is related to its work in squeezing through capillaries. It is necessary to investigate the erythrocytes morphological changes (deformation). The existence of erythrocyte deformation or the morphological changes may relate to the abnormal function of blood. For example, a previous study showed that the erythrocyte deformation was related to the sickle cell disease (Charrin et al., 2016). Similarly, any alteration due to erythrocytes deformation becomes a marker of iron deficiency anemia and thalassemia (Zhang et al., 2012), as well as the sickle cell disease (Charrin et al., 2016).

Our findings suggest that the cell alteration by exposure to ultrafine particles is confined to the erythrocyte deformation. In this study, unexposed mice (control group) had healthier erythrocytes with normal biconcave cells, and on the contrary, the exposed mice showed a positive correlation with the abnormal erythrocytes $(p<0.05)$ (Fig. 3). In addition to the cell alteration, the deformation of the mice erythrocytes can be linked to the cell physical alteration (Yoon and You, 2016) and the existence of eryptosis, suicidal death erythrocytes (Mischitelli et al., 2016). Consistent with this assessment, we found that deformation level, as well as the deformed erythrocytes, were significantly increased in the mice exposed to the ultrafine particles. The deformation effects of the exposure to ultrafine particles are in accordance with a previous study (Wardoyo et al., 2017), confirming that exposure to ultrafine particles contained in the motorcycle exhaust emission induces erythrocytes deformation, such as sickle-shaped cells, teardrop-shaped cells, and helmet-shaped cells, which then increase the level of erythrocyte deformation.

This study corroborates previous findings obtained from mice exposed to acute ultrafine particles contained in the motorcycle exhaust emission (ten consecutive days), implicating the deformation effects in the mice tubular epithelial cells (Wardoyo et al., 2018) and erythrocytes (Wardoyo et al., 2017). Consistent with this result, erythrocytes are highly deformable and may also exhibit reduced deformability and stronger aggregation in many pathological situations, such as sickle cell anemia (Popel and Johnson, 2005). Eryptosis itself can be triggered by any kind of erythrocyte injury, including oxidative stress due to reactive oxygen species (Mischitelli et al., 2016). This deformation effect is likely to be due to the continuous exposure of diesel exhaust particles which alter the lipid bilayer. This suggests that an important role may exist between exposure to diesel exhaust particles and erythrocyte deformation, oxidative stress, and chronic inflammation. Interestingly, there is a significant correlation between erythrocyte deformability and oxidative stress and chronic inflammation markers (Gyawali et al., 2015). This probably may develop due to the erythrocyte responses in countering the effects of oxidative stress and chronic inflammation. Oxidation of membrane lipids and proteins may alter the erythrocytes (Richards et al., 1998).

The oxidative stress and chronic inflammation can be related to the production of reactive oxygen species (Jantzen et al., 2016). The generation of reactive oxygen species due to the exposure to ultrafine particles might be related to the cytotoxic effect 
on endothelial cells (Mo et al., 2012). Reactive oxygen species can be related to the translocation of particles. When particles transport through the bloodstream or lymphatic system to vital organs, they can cross the lung-blood barrier and translocate into the blood circulation, unite to erythrocytes, and disturb the cation transport on the membrane causing erythrocytes deformation (Li et al., 2008, Delfino et al., 2005). This deformation can be linked to the decreasing amount of mice antioxidant (becoming the free radicals generators) (Kampa and Castanas, 2008). However, the effect of deposited particulate matters in altering the mice erythrocytes was found in some abnormal forms of erythrocytes. Diesel exhaust particles exposures indeed had a significant role in generating the inflammatory and genotoxic effects (Hougaard et al., 2008). The form of a normal erythrocyte in the two-dimensional model is a biconcave capsule, and its radius is $\pm 3.91 \mu \mathrm{m}$ (Zhang et al., 2009). However, this form may change due to the existence of particles, as explained above. In addition, the most erythrocytes found in our research are in a normal form. This state becomes the evidence that not all erythrocytes can be influenced by the particles. We consider that the membrane rigidity prevents large deformation and large cell contact area, resulting in a less dense erythrocytes cores (Zhang et al., 2009). Moreover, the deformations were influenced by some factors, such as neo-Hookean elastic (Bagchi et al., 2005) and the local tangential and the normal directions of the membrane (Zhang et al., 2009). The above analysis conveyed that the possible interactions occurred between exposure to diesel exhaust particles and erythrocyte deformability.

Motor vehicle emission may consist of polycyclic aromatic hydrocarbons (Lai et al., 2013) and volatile organic compounds (Ge et al., 2018). Similarly, previous studies measured the substances of particulate matters emitted by motor vehicles, including polycyclic aromatic hydrocarbons and volatile organic compounds (Pham et al., 2013, Yan et al., 2015, Wierzbicka et al., 2014). Epidemiologic studies have investigated the toxic impacts related to the exposure to polycyclic aromatic hydrocarbons and volatile organic compounds. Polycyclic aromatic hydrocarbon substances, such as anthracene, phenanthrene, fluoranthene, benzo(a)pyrene, pyrene, and naphthalene, and many other forms are well-known to be the carcinogens for human health (Tongo et al., 2017, Sarigiannis et al., 2015, Bortey-Sam et al., 2017, Louis et al., 2016, Pham et al., 2013). On the other hand, volatile organic compounds also become hazardous chemicals and toxic to human health due to the carcinogenic and mutagenic characteristics (Kumar et al., 2018).

\section{Conclusion}

In conclusion, diesel exhaust ultrafine particles significantly affect the mice erythrocyte deformation. The dose concentration of diesel exhaust ultrafine particles have an influence on the erythrocyte deformation level. The more diesel ultrafine particles mice were exposed to the more damage to the erythrocytes was observed. The correlation between the ultrafine particle exposure and the erythrocyte deformation was obtained proportionally with the $R^{2}>0.85$.

Acknowledgements. All the authors are grateful to Directorate General of Higher Education, for providing funding for conducting this research project. The kind hands of Arif Budianto, Mia Anggun P., Eko T.P.A., Arsyal K.R., Renado Anggara, and M. Nurhuda Arifandi involving in this study are gratefully acknowledged. 


\section{REFERENCES}

[1] Bagchi, P., Johnson, P.C., Popel, A.S. (2005): Computational fluid dynamic simulation of aggregation of deformable cells in a shear flow. - Journal of Biomechanical Engineering 127(7): 1070-1080.

[2] Bortey-Sam, N., Ikenaka, Y., Akoto, O., Nakayama, S.M.M., Asante, K.A., Baidoo, E., Obirikorang, C., Saengtienchai, A., Isoda, N., Nimako, C., Mizukawa, H., Ishizuka, M. (2017): Oxidative stress and respiratory symptoms due to human exposure to polycyclic aromatic hydrocarbons (PAHs) in Kumasi, Ghana. - Environmental Pollution 228: 311320.

[3] Cannizzaro, V., Berry, L.J., Nicholls, P.K., Zosky, G.R., Turner, D.J., Hantos, Z., Sly, P.D. (2009): Lung volume recruitment maneuvers and respiratory system mechanics in mechanically ventilated mice. - Respiratory Physiology and Neurobiology 169(3): 243251.

[4] Charrin, E., Ofori-Acquah, S.F., Nader, E., Skinner, S., Connes, P., Pialoux, V., Joly, P., Martin, C. (2016): Inflammatory and oxidative stress phenotypes in transgenic sickle cell mice. - Blood Cells, Molecules, and Diseases 62: 13-21.

[5] Delfino, R.J., Sioutas, C., Malik, S. (2005): Review potential role of ultrafine particles in associations between airborne particle mass and cardiovascular health. - Environmental Health Perspectives 113(8): 934-947.

[6] Eeftens, M., Phuleria, H.C., Meier, R., Aguilera, I., Corradi, E., Davey, M., Ducret-Stich, R., Fierz, M., Gehrig, R., Ineichen, A., Keidel, D., Probst-Hensch, N., Ragettli, M.S., Schindler, C., Künzli, N., Tsai, M.-Y. (2015): Spatial and temporal variability of ultrafine particles, NO2, PM2.5, PM2.5 absorbance, PM10 and PMcoarse in Swiss study areas. Atmospheric Environment 111(2): 60-70.

[7] Ge, J.C., Kim, H.Y., Yoon, S.K., Choi, N.J. (2018): Reducing volatile organic compound emissions from diesel engines using canola oil biodiesel fuel and blends. - Fuel 218(January): 266-274.

[8] Gyawali, P., Richards, R.S., Bwititi, P.T., Nwose, E.U. (2015): Association of abnormal erythrocyte morphology with oxidative stress and inflammation in metabolic syndrome. Blood Cells, Molecules, and Diseases 54(4): 360-363.

[9] Hemmingsen, J.G., Hougaard, K.S., Talsness, C., Wellejus, A., Loft, S., Wallin, H., Møller, P. (2009): Prenatal exposure to diesel exhaust particles and effect on the male reproductive system in mice. - Toxicology 264: 61-68.

[10] Hougaard, K.S., Jensen, K.A., Nordly, P., Taxvig, C., Vogel, U., Saber, A.T., Wallin, H. (2008): Effects of prenatal exposure to diesel exhaust particles on postnatal development, behavior, genotoxicity and inflammation in mice. - Particle and Fibre Toxicology 5(3).

[11] Jantzen, K., Møller, P., Karottki, D.G., Olsen, Y., Bekö, G., Clausen, G., Hersoug, L.G., Loft, S. (2016): Exposure to ultrafine particles, intracellular production of reactive oxygen species in leukocytes and altered levels of endothelial progenitor cells. Toxicology 359-360: 11-18.

[12] Kampa, M., Castanas, E. (2008): Human health effects of air pollution. - Environmental pollution (Barking, Essex : 1987) 151(2): 362-367.

[13] Kumar, A., Singh, D., Kumar, K., Singh, B.B., Jain, V.K. (2018): Distribution of VOCs in urban and rural atmospheres of subtropical India: Temporal variation, source attribution, ratios, OFP and risk assessment. - Science of the Total Environment 613614: 492-501.

[14] Lai, C.-H., Chuang, K.-Y., Chang, J.-W. (2013): Characteristics of nano-/ultrafine particle-bound PAHs in ambient air at an international airport. - Environmental science and pollution research international 20(3): 1772-80.

[15] Li, S.-Q., Zhu, R.-R., Zhu, H., Xue, M., Sun, X.-Y., Yao, S.-D., Wang, S.-L. (2008): Nanotoxicity of $\mathrm{TiO} 2$ nanoparticles to erythrocyte in vitro. - Food and Chemical Toxicology 46(12): 3626-3631. 
[16] Louis, C., Liu, Y., Tassel, P., Perret, P., Chaumond, A., Andre, M. (2016): PAH, BTEX, carbonyl compound, black-carbon, $\mathrm{NO} 2$ and ultrafine particle dynamometer bench emissions for Euro 4 and Euro 5 diesel and gasoline passenger cars. - Atmospheric Environment 141(2): 80-95.

[17] Mischitelli, M., Jemaa, M., Almasry, M., Faggio, C., Lang, F. (2016): Triggering of suicidal erythrocyte death by fascaplysin. - Cellular Physiology and Biochemistry 39(September): 1638-1647.

[18] Mo, Y., Wan, R., Feng, L., Chien, S., Tollerud, D.J., Zhang, Q. (2012): Combination effects of cigarette smoke extract and ambient ultrafine particles on endothelial cells. Toxicology in vitro : an international journal published in association with BIBRA 26(2): 295-303.

[19] Pham, C.T., Kameda, T., Toriba, A., Hayakawa, K. (2013): Polycyclic aromatic hydrocarbons and nitropolycyclic aromatic hydrocarbons in particulates emitted by motorcycles. - Environmental Pollution 183: 175-183.

[20] Popel, A.S., Johnson, P.C. (2005): Microcirculation and hemorheology. - Annual Review of Fluid Mechanics 37(1): 43-69.

[21] Richards, R.S., Roberts, T.K., McGregor, N.R., Dunstan, R.H., Butt, H.L. (1998): The role of erythrocytes in the inactivation of free radicals. - Medical Hypotheses 50(5): 363367.

[22] Sarigiannis, D.A., Karakitsios, S.P., Zikopoulos, D., Nikolaki, S., Kermenidou, M. (2015): Lung cancer risk from PAHs emitted from biomass combustion. - Environmental Research 137: 147-156.

[23] Stewart, J.C., Chalupa, D.C., Devlin, R.B., Frasier, L.M., Huang, L., Little, E.L., Lee, S.M., Richard, P., Anthony, P., Taubman, M.B., Utell, M.J., Frampton, M.W. (2010): Vascular effects of ultrafine particles in persons with type 2 diabetes. - Environmental Health Perspectives 118(12): 1692-1699.

[24] Tongo, I., Ogbeide, O., Ezemonye, L. (2017): Human health risk assessment of polycyclic aromatic hydrocarbons (PAHs) in smoked fish species from markets in Southern Nigeria. - Toxicology Reports 4: 55-61.

[25] Waly, M.I., Ali, B.H., Nemmar, A. (2013): Acute effects of diesel exhaust particles and cisplatin on oxidative stress in cultured human kidney (HEK 293) cells, and the influence of curcumin thereon. - Toxicology in Vitro 27(8): 2299-2304.

[26] Wang, F., Gao, F., Lan, M., Yuan, H., Huang, Y., Liu, J. (2009): Oxidative stress contributes to silica nanoparticle-induced cytotoxicity in human embryonic kidney cells. - Toxicology in Vitro 23(5): 808-815.

[27] Wang, T., Miao, M., Bai, M., Li, Y., Li, M., Li, C., Xu, Y. (2017): Effect of sophora japonica total flavonoids on pancreas, kidney tissue morphology of streptozotocininduced diabetic mice model. - Saudi Journal of Biological Sciences 24(3): 741-747.

[28] Wardoyo, A.Y.P., Juswono, U.P., Noor, J.A.E. (2017): A study of the correlation between ultrafine particle emissions in motorcycle smoke and mice erythrocyte damages. - Experimental and Toxicologic Pathology 69(8): 649-655.

[29] Wardoyo, A.Y.P., Juswono, U.P., Noor, J.A.E. (2018): Varied dose exposures to ultrafine particles in the motorcycle smoke cause kidney cell damages in male mice. - Toxicology Reports 5: 383-389.

[30] Wardoyo, A.Y.P., Morawska, L., Ristovski, Z.D., Jamriska, M., Carr, S., Johnson, G. (2007): Size distribution of particles emitted from grass fires in the Northern Territory, Australia. - Atmospheric Environment 41(38): 8609-8619.

[31] Wierzbicka, A., Nilsson, P.T., Rissler, J., Sallsten, G., Xu, Y., Pagels, J.H., Albin, M., Österberg, K., Strandberg, B., Eriksson, A., Bohgard, M., Bergemalm-rynell, K., Gudmundsson, A. (2014): Detailed diesel exhaust characteristics including particle surface area and lung deposited dose for better understanding of health effects in human chamber exposure studies. - Atmospheric Environment 86: 212-219. 
[32] Xu, Y., Barregard, L., Nielsen, J., Gudmundsson, A., Wierzbicka, A., Axmon, A., Jönsson, B.A.G., Kåredal, M., Albin, M. (2013): Effects of diesel exposure on lung function and inflammation biomarkers from airway and peripheral blood of healthy volunteers in a chamber study. - Particle and Fibre Toxicology 10(60): 1-9.

[33] Yan, C., Zheng, M., Yang, Q., Zhang, Q., Qiu, X., Zhang, Y., Fu, H., Li, X., Zhu, T., Zhu, Y. (2015): Commuter exposure to particulate matter and particle-bound PAHs in three transportation modes in Beijing, China. - Environmental Pollution 204: 199-206.

[34] Yoon, D., You, D. (2016): Continuum modeling of deformation and aggregation of red blood cells. - Journal of Biomechanics 49(11): 2267-2279.

[35] Zhang, J., Johnson, P.C., Popel, A.S. (2009): Effects of erythrocyte deformability and aggregation on the cell free layer and apparent viscosity of microscopic blood flows. Microvascular Research 77(3): 265-272.

[36] Zhang, Y., Zhang, W., Wang, S., Wang, C., Xie, J., Chen, X., Xu, Y. Mao, P. (2012): Detection of human erythrocytes influenced by iron deficiency anemia and thalassemia using atomic force microscopy. - Micron 43(12): 1287-1292. 